\title{
Direct determination of selected metals in refractory powder micro samples with exploding thin film excitation
}

\author{
Elke M. Clark and Richard D. Sacks* \\ Department of Chemistry, University of Michigan, Ann Arbor, MI 48109, U.S.A.
}

(Received 19 February 1980)

\begin{abstract}
The direct determination of metallic elements in powder micro samples is explored. Emphasis is placed on refractory materials prepared as alcoholic suspensions of their powders. Silver thin films are vacuum deposited on polypropylene strips and on polycarbonate membrane filters. Based on a parametric study, explosions conducted at 700 torr in $\operatorname{Ar}(60 \%)-\mathrm{O}_{2}(40 \%)$ using $4 \mathrm{kV}, 180 \mathrm{~J}$ discharges are most satisfactory. Particle size studies suggest complete vaporization of particles smaller than $\sim 10 \mu \mathrm{m}$ independent of their boiling points. High circuit inductance and capacitance as well as $\mathrm{O}_{2}$ added to the plasma support gas promote vaporization of larger particles. Particles which pass through a $5 \mu \mathrm{m}$ mesh sieve can be analyzed with aqueous solution standards. Analytical curves and precision data are presented for $\mathrm{Zr}, \mathrm{V}, \mathrm{Mo}$ and Ni. Interparticle concomitant effects are not significant. Feasibility studies are presented for the direct analysis of airborne particles collected on metallized membrane filters.
\end{abstract}

\section{INTRODUCTION}

THE DIRECT determination of metallic elements in solid, particulate material is of growing importance in many areas of science and technology. Examples include airborne particulate material usually collected on filters, suspended particulate material in public water systems, crushed geological specimens and solid wear metals in lubricating oil. Other solid samples, often refractory in nature and of particular interest in materials science and the nuclear industry, often can be crushed and determined as solid particles.

Because of the complexity of the solid matrix and the attendant difficulties in standard preparation, procedures for these samples often involve time consuming matrix exchange operations to render soluble the inorganic portion of the sample followed by analysis using various atomic spectroscopic methods. Sample loss, contamination and insoluble siliceous residues as well as protracted analysis time have stimulated considerable interest in direct methods for solids.

Direct current arc excitation has been used for many years for the direct analysis of powders packed into graphite electrodes $[1,2]$. However, severe concomitant effects, mediocre precision and difficulties with refractory samples have prompted studies with alternative methods. L'vov [3] has reviewed the trace charactcrization of powders by atomic absorption spectrometry. The usual open-type graphite furnaces used for electrothermal atomization of solution residues were not found satisfactory for powders because the evolution of gases during sample vaporization often resulted in the ejection of the sample from the furnace. A sealed, porous graphite furnace heated in a combustion flame was found most satisfactory. Sample vapor emerges through the porous furnace walls. Absolute sensitivities generally are in the $10^{-9}$ to $10^{-11} \mathrm{~g}$ range [4]. Govindaraju, Mevelle and Chouard [5] note that solid sampling atomic absorption analysis is very rarely recommended in analytical geochemistry. They investigated

* Author to whom correspondence should be addressed.

[1] L. H. Ahrens and S. R. Taylor, Spectrochemical Analysis, 2nd edition, Addison-Wesley, Reading (1961).

[2] C. E. Harvey, Spectrochemical Procedures. Applied Research Laboratories, Glendale (1950).

[3] B. V. L'Vov, Talanta 23, 109 (1976).

[4] D. A. Katskov, L. P. Kruglikova and B. V. L'Vov, Zh. Analit. Khim. 30, 328 (1975).

[5] K. Govindaraju, G. Mevelle and C. Chouard, Anal. Chem. 46, 1672 (1974). 
a procedure where a powdered rock sample is impregnated on an iron screw rod which is heated in a combustion flame. Lead was determined at ppm levels in $45-75 \mathrm{mg}$ samples. WILlis [6] used a commerical spray chamber nebulizer to spray aqueous suspensions of crushed solids into a combustion flame. Particle size effects are rather significant, and only particles of less than $10-$ to $12-\mu \mathrm{m}$ diameter contribute significantly to the observed atomic absorption.

WHITEHEAD and HEADY [7] used a laser microprobe with spark excitation for the determination of trace elements homogeneously distributed in powdered materials. Detection limits were comparable to d.c. arc values. With an internal reference procedure, coefficients of variation were in the 5-20\% range. Matrix effects, while smaller than with d.c. are excitation, were not insignificant.

While inductively coupled plasma optical emission spectroscopy may prove useful for the direct analysis of powders, little analytical data has appeared. BARNES and NiKDEL [8] recently used computer simulations to suggest significant particle size effects, particularly for the relatively low power, Ar supported plasmas used in commerical analytical instrumentation.

The direct analysis of airborne particulate material collected on filters using X-ray fluorescence [9] is finding increasing application. While sample preparation is minimal, and precision is good, powers of detection generally are poorer than with atomic spectroscopy in the optical wavelength region. This often results in protracted sample collection time. Particle size effects are very significant, and dichotomous sampling often is required. Compound form effects also are significant. CRISs [10] has developed an empirical correction scheme for particle size and compound form effects. The lack of reliable particle size standards, however, makes it difficult to check this correction scheme. Other problems occur in X-ray fluorescence when particles shield each other or when they penetrate into a coarse substrate [11].

While these methods hold considerable promise, no single approach has been evaluated sufficiently to demonstrate a comprehensive solution to the multielement determination problem in solid, particulate material.

Thin metal films electrically exploded by capacitive discharge recently have been used as atomization cells and excitation sources for the determination of selected trace metals in micro-volume aqueous solution samples [12-14]. While these studies were only preliminary, they did suggest some analytically attractive features including a 3-4 order of magnitude dynamic concentration range, relatively minor concomitant effects and the possibility of sufficiently high plasma temperature to obtain atomization of refractory samples.

This report presents results of experiments using electrically exploded thin Ag films for the atomization and excitation of microsize powder samples. Samples are introduced onto the thin film surfaces as micro volumes of powders suspended in alcohol or by passing a particle laden air stream through membrane filters which had one surface metallized with a thin $\mathrm{Ag}$ film. Emphasis is placed on refractory materials, including the carbides of $\mathrm{V}, \mathrm{Zr}$ and $\mathrm{Mo}$, for several reasons. First, they represent an important class of solids in many technologies including nuclear energy. Second, their very low solubilities favor their analysis as solids, and finally, their very high boiling points render difficult their atomization and thus provide a genuine test for any atomization cell.

[6] J. B. WILlis, Anal. Chem. 47, 1753 (1975).

[7] A. B. Whitehead and H. H. Heady, Appl. Spectry 22, 7 (1968).

[8] R. M. BARNeS and S. NikdEL, Appl. Spectry 30, 310 (1976).

[9] R. K. Stevens and T. G. Dzubay, Atmospheric Environment 12, 55 (1978).

[10] J. W. Criss, Anal. Chem. 48, 179 (1976).

[11] T. G. DzubaY and R. O. Nelson, Adv. X-Ray Anal. 18, 619 (1975).

[12] D. V. DuChane and R. D. SACKs, Anal. Chem. 50, 1752 (1978).

[13] R. D. Sacks and D. V. Duchane, Anal. Chem. 50, 1757 (1978).

[14] D. V. Dcuhane and R. D. SACKs, Anal. Chem. 50, 1765 (1978). 


\section{Apparatus and Techniques}

2.1 Film preparation. Thin Ag films were prepared by conventional vacuum deposition techniques. The vacuum deposition chamber has been described [15]. Films were prepared on polypropylene strips and on polycarbonate membrane filters. Table 1 summarizes properties of the $\mathrm{Ag}$ films and substrates used in this study.

2.2 Film cassettes. Figure 1 shows the film cassette used to accommodate the rectangular substrates. The base consists of two T-shaped copper contacts fastened to a $\mathrm{T}$-shaped polycarbonate block. A semi-circle is cut in the base of each contact, which matches the diameter of brass rod electric feedthroughs in the wall of the explosion chamber. A $1.5-\mathrm{cm}$ wide, $0.15-\mathrm{cm}$ deep groove on the top surface of the polycarbonate block allows reproducible positioning of the polypropylene substrate strips. Electrical contact to the film is provided by cylindrical, $1.25-\mathrm{cm}$ diameter carbon electrodes, which are recessed in $\mathrm{Cu}$ blocks and held in place by set screws. Polycarbonate shields prevent sparkover to the exposed metal parts. Brass thumbscrews are used to fasten the electrode assemblies to the lower $\mathrm{Cu}$ bases as well as for electrical feedthrough from the lower $\mathrm{Cu}$ support blocks to the carbon electrodes. Figure 2(a) shows the cassette for the circular membrane substrates. To avoid unnecessary handling of the fragile membranes and any coinciding loss of sample, the cassette was designed to accommodate part of the sample introduction apparatus. The base contacts of the cassette are similar to those described above. The top surface of each $\mathrm{Cu}$ contact is machined to form a $2.8-\mathrm{cm}$ radius circular segment. This matches the radius of the membrane support, which is described in the following section. Electrical contact to the thin film is made by two arc-shaped, high purity carbon electrodes, which are pressed against the thin film by $\mathrm{Cu}$ plates. These plates are fastened to the $\mathrm{Cu}$ bases with brass thumbscrews.

2.3 Filter collection apparatus. The apparatus shown in Fig. 2(b) was used to simulate the collection of dry powder samples suspended in an air stream. A $1.7-\mathrm{cm}$ high, $6-\mathrm{cm}$ i.d. brass cylinder forms the base. A 1-cm diameter brass tube at the bottom provides connection to a rotameter-type flowmeter and a vacuum pump. A $7.5-\mathrm{mm}$ wide ledge located $1 \mathrm{~cm}$ from the top of the cylinder supports the membrane holder on a rubber O-ring. The membrane holder is a polycarbonate disk, into which a combination of concentric rings and slots is milled. This provides a uniform air flow through the exposed membrane surface. A polycarbonate retainer ring keeps the edges of the membrane pressed against the holder when suction is applied. A cone-shaped A1 lid

Table 1. Properties of the thin films and substrates

\begin{tabular}{|c|c|}
\hline \multicolumn{2}{|l|}{ Ag films on polypropylene strips } \\
\hline Substrate dimensions, $\mathrm{cm}$ & $7.3 \times 1.5 \times 0.15$ \\
\hline Film dimensions, $\mathrm{cm}$ & $6.5 \times 1.5$ \\
\hline Surface area exploded, $\mathrm{cm}^{2}$ & 7.9 \\
\hline Film thickness* $\AA$ & 260 \\
\hline Film mass exploded $\dagger, \mu \mathrm{g}$ & 216 \\
\hline Resistance, $\Omega$ & $6 \pm 0.5$ \\
\hline \multicolumn{2}{|l|}{ Ag films on polycarbonate filters } \\
\hline Substrate dimensions, $\mathrm{mm}$ & 47 dia. $\times 0.01$ thick \\
\hline Pore diameter, $\mu \mathrm{m}$ & 3 \\
\hline Film diameter, $\mathrm{mm}$ & 41 \\
\hline Film thickness*, ${ }^{*}$ & 280 \\
\hline Film mass exploded $\dagger, \mu \mathrm{g}$ & 370 \\
\hline Resistance (across diameter), $\Omega$ & $3.5 \pm 0.2$ \\
\hline
\end{tabular}

[15] E. M. Clark, Ph.D. Dissertation. University of Michigan, Ann Arbor, MI (1979). 


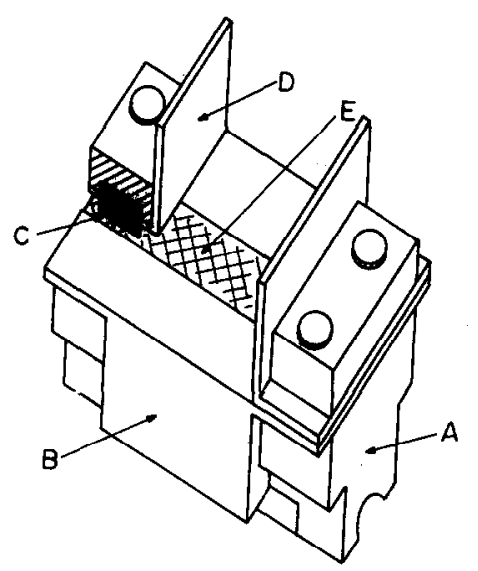

Fig. 1. Thin film explosion cassette for polypropylene substrate strips. (A) Cu contact; (B) polycarbonate block; (C) carbon electrode; (D) polycarbonate shield; (E) thin film on polypropylene substrate.

screws onto the base and allows for air flow through the 1-cm diameter opening at the top. Tygon tubing connects a disposable glass pipette to the air inlet.

2.4 Sample introduction. Ten-microliter aqueous solution samples were placed on $\mathrm{Ag}$ films with a disposable tip micropipette. The water was evaporated under a heat lamp. Powder samples were applied as $10-\mu 1$ isopropyl alcohol suspensions. Milligram amounts of weighed sample were used with sufficient alcohol to obtain $\mu \mathrm{g}$ quantities of sample on the film surface. Alcohol suspensions were preferred to water suspensions since they resulted in a more uniform particle distribution on the film surface. During sample application the suspension was continuously stirred. Once the sample was pipetted onto the $\mathrm{Ag}$ film, the alcohol was evaporated under a heat lamp.

Powder samples used with the metallized membrane filters were mixed with $\mathrm{Al}_{2} \mathrm{O}_{3}$ powder such that the analyte was present at the $1 \%$ level by weight. This dilution was necessary to reduce weighing errors as well as sample loss by impactation on the walls of the plastic tubing used to transport the sample to the filter. A Wig-L-Bug was used to mix the two components. A $0.5 \mathrm{mg}$ portion of the mixture was weighed on a microbalance, and a $0.581 \mathrm{~min}^{-1}$ air flow was used to vacuum the sample directly from

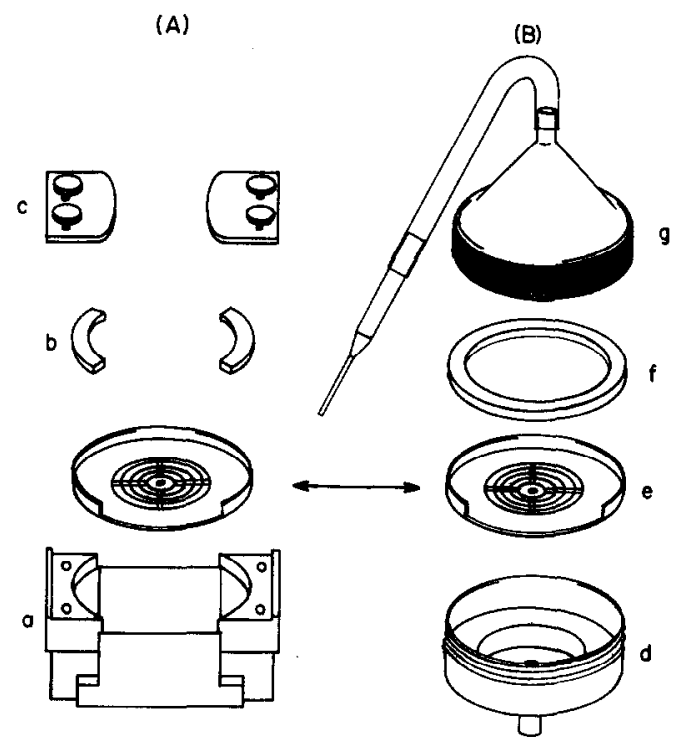

Fig. 2. Film explosion cassette and sample collection system for metallized membrane filters. (A) film explosion cassette; a, polycarbonate base; b, carbon electrodes; c, copper clamp; (B) sample collection system; d, base; e, filter support; f, retainer ring; $g$, lid. 
the balance pan through the orifice of the disposable glass pipette onto the filter surface. At this flow rate, the particles are confined to a region $\sim 3-\mathrm{cm}$ diameter at the filter center. At lower flow rates, some powder was lost to the membrane holder. After sample collection, the membrane and holder were transferred to the explosion cassette.

2.5 Particle sizing. All powder materials used for particle size studies were separated commercially by the ATM Corp., Sonic Sifter Division, Greendale, Wis. To establish the average particle size, isopropyl alcohol suspensions of each size fraction were deposited on carbon disks and photographed through a Jeol JSM-U3 scanning electron microscope. The longest distance on the surface of the particle was used as a measure of particle size.

2.6 General apparatus and procedures. The capacitive discharge circuit used for the explosive vaporization of thin films has been described [12]. The explosion chamber also is similar to one previously described [12]. Current waveforms from the discharge were obtained with a current-voltage transformer (Model 1025, Pearson Electronics) and displayed on a Nicolet Model 1090A digital storage oscilloscope.

All spectra were recorded on Kodak SAl plates with a $1.0-\mathrm{m}$ Czerny Turner spectrometer (Jarrell-Ash Model 78-460) having a first order reciprocal dispersion of $0.8 \mathrm{~nm} \mathrm{~mm}^{-1}$. The explosion chamber was placed $25 \mathrm{~cm}$ from the spectrometer, and no auxiliary optics were used.

2.6 Materials and reagents. Silver as 100 -mesh needles with $99.999 \%$ minimum purity was used for thin films production. Aqueous solution samples were prepared daily from $1000-\mu \mathrm{g} \mathrm{ml}^{-1}$ stock solutions of reagent-grade salts. Powder samples were prepared from reagent-grade materials. Powder suspensions were prepared in reagentgrade isopropyl alcohol. Table 2 presents boiling points of the compounds as well as the spectral lines used in this study.

\section{Basic Analytical Considerations}

All the studies discussed in this section were conducted using $180 \mathrm{~J}, 4 \mathrm{kV}$ discharges in an $\operatorname{Ar}(60 \%)-\mathrm{O}_{2}(40 \%)$ atmosphere at 700 torr. These parameters were chosen after a parametric study which is detailed in reference [15]. The explosion conditions chosen optimize line-to-background intensity ratios and precision. All data represent averages of five determinations at the indicated concentrations.

\subsection{Analytical curves}

Figure 3 shows analytical curves for $\mathrm{Mo}_{2} \mathrm{C}, \mathrm{ZrC}, \mathrm{VC}$ and $\mathrm{V}_{2} \mathrm{~S}_{3}$. These curves were constructed with data obtained from powder samples suspended in isopropyl alcohol.

Table 2. Compound boiling points and analysis lines

\begin{tabular}{|c|c|c|c|c|}
\hline Element & $\begin{array}{l}\text { Chemical } \\
\text { form }\end{array}$ & $\begin{array}{l}\text { Boiling } \\
\text { point(K) }\end{array}$ & $\begin{array}{l}\text { Analysis } \\
\text { line (nm) }\end{array}$ & $\begin{array}{c}\text { Excitation } \\
\text { potential }(\mathrm{eV})\end{array}$ \\
\hline \multirow[t]{2}{*}{$\mathrm{Ag}$} & $\mathrm{Ag}$ & 2485 & (I) 346.9 & 3.6 \\
\hline & & & (I) 309.9 & 4.0 \\
\hline \multirow[t]{2}{*}{$\mathrm{Mn}$} & $\mathrm{Mn}$ & 2150 & (II) 294.9 & 5.4 \\
\hline & $\mathrm{Mn}\left(\mathrm{NO}_{3}\right)_{2} \cdot 4 \mathrm{H}_{2} \mathrm{O}$ & 402 & & \\
\hline \multirow[t]{3}{*}{ Mo } & $\mathrm{Mo}_{2} \mathrm{C}$ & D 2800 & (I) 390.2 & 3.2 \\
\hline & $\left(\mathrm{NH}_{4}\right)_{2} \mathrm{MoO}_{4}$ & - & (I) 313.2 & 3.9 \\
\hline & & & (II) 284.8 & 5.95 \\
\hline \multirow[t]{2}{*}{$\mathrm{Ni}$} & $\mathrm{Ni}$ & 2905 & (I) 341.4 & 3.6 \\
\hline & $\mathrm{Ni}\left(\mathrm{NO}_{3}\right)_{2} \cdot 6 \mathrm{H}_{2} \mathrm{O}$ & 414 & & \\
\hline \multirow[t]{4}{*}{ V } & VC & 4200 & (I) 318.3 & 3.9 \\
\hline & $\mathrm{V}_{2} \mathrm{~S}_{3}$ & D 800 & (II) 310.2 & 4.36 \\
\hline & $\mathrm{V}_{2} \mathrm{O}_{3}$ & D 2000 & (II) 292.4 & 4.6 \\
\hline & $\mathrm{NH}_{4} \mathrm{VO}_{3}$ & D 680 & & 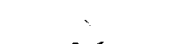 \\
\hline \multirow[t]{2}{*}{$\mathrm{Zr}$} & $\mathrm{ZrC}$ & 5370 & (I) 360.1 & 3.6 \\
\hline & $\mathrm{Zr}\left(\mathrm{SO}_{4}\right)_{2} \cdot 4 \mathrm{H}_{2} \mathrm{O}$ & D 680 & (II) 343.8 & 3.65 \\
\hline
\end{tabular}




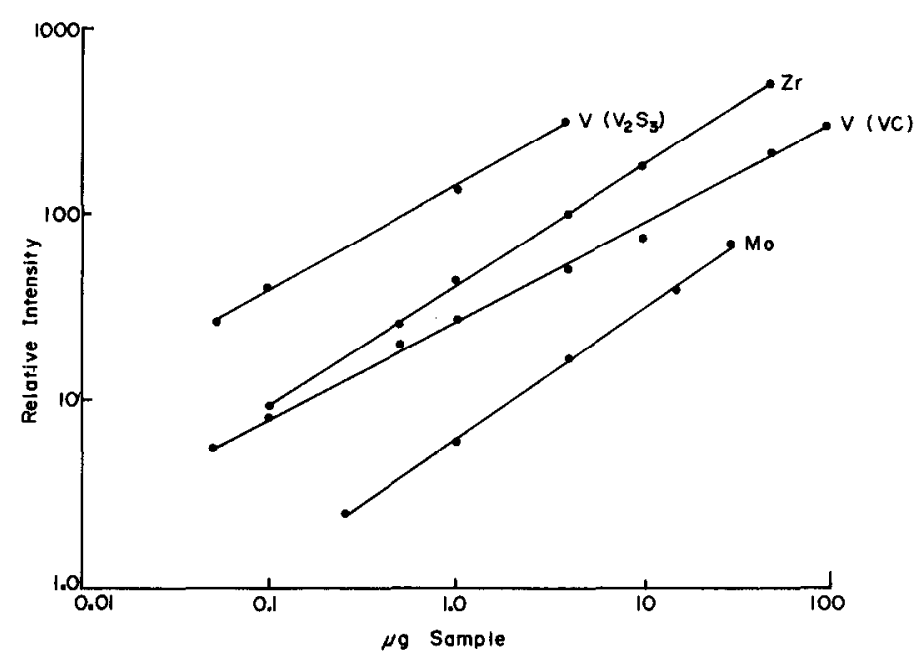

Fig. 3. Analytical curves for $\mathrm{Mo}_{2} \mathrm{C}, \mathrm{ZrC}, \mathrm{VC}$ and $\mathrm{V}_{2} \mathrm{~S}_{3}$ powder samples.

These powders encompassed particles ranging from 70 to less than $5 \mu \mathrm{m}$ in diameter. Relative S.D. for these data all fell within the $5-17 \%$ range. The linear dynamic concentration range of these $\log$ - $\log$ plots varies from two decades for Mo to over three decades for $\mathrm{V}$.

The slopes of these curves all are less than unity. This may be duc to a nonlinearity in the atomization or excitation process or to a failure in the emulsion response.

\subsection{Reproducibility}

Throughout this work, five replicate determinations of the powder samples gave relative S.D. of measured intensities ranging from 5 to $20 \%$; while, in general, the values the $\mathrm{Ag}$ line intensities from the thin films ranged from 3 to $10 \%$. The lower values in these ranges approach the limits imposed by photographic detection. The $\mathrm{Ag}$ thin films appear to vaporize rapidly and completely from ohmic heating during the initial current surge before dielectric breakdown occurs in the surrounding gas $[12,13]$. Thus, random fluctuations in the parameters characterizing the plasma in the initial stages effect only the Ag excitation and not the vaporization processes. The very high boiling points of the analyte materials used in this study, as well as corroborating data presented below, suggest that these sample powders are vaporized primarily through interaction with the hot plasma gases. Thus the component of the variance introduced by plasma fluctuations would be larger for analyte species than for the $\mathrm{Ag}$ film material.

Since most of the studies reported here used relatively small samples $(1-5 \mu \mathrm{g})$, the number of particles in the samples often was so small that sampling uncertainty made a significant contribution to the total variance. For a sample containing $N$ identical particles, the S.D. in the number of particles in randomly drawn aliquots of the suspension is estimated as

$$
\% \text { Relative S.D. }=100 N^{-1 / 2} \text {. }
$$

A $1.0 \mu \mathrm{g}$ sample of $8.9 \mu \mathrm{m}$ diameter VC particles contains $\sim 470$ particles with a $4.6 \%$ S.D. For $2.8 \mu \mathrm{m}$ diameter particles the S.D. decreases to $0.8 \%$; while for $12.5 \mu \mathrm{m}$ particles, it increases to more than $18 \%$. Precision data were obtained for powder samples which passed through a $5-\mu \mathrm{m}$ pore diameter sieve and for aqueous solution samples of the same elements and sample mass. Results are shown in Table 3. The precision obtained for the suspended particles, in general, is comparable to the values obtained for the solution samples. Microscopic examination of the powder samples confirmed that nearly all particles were less than $5 \mu \mathrm{m}$ in diameter. This should result in a sampling uncertainty of less than $2 \%$. 
Table 3. Relative S.D. for solid and aqueous samples

\begin{tabular}{ccc}
\hline & \multicolumn{2}{c}{ Relative S.D. (\%) } \\
Analyte & Powder & Aqueous \\
\hline $\mathrm{V}$ & 11.2 & 17.3 \\
$\mathrm{Ni}$ & 10.4 & 7.9 \\
$\mathrm{Zr}$ & 6.7 & 7.0 \\
$\mathrm{Mn}$ & 6.7 & 9.9 \\
$\mathrm{Mo}$ & 15.3 & 11.0 \\
\hline
\end{tabular}

\subsection{Concomitant effects}

Direct methods for the determination of metallic elements in solids such as d.c. arc and laser microprobe excitation often result in more severe concomitant effect than solution methods [16]. This is due in part to the complexity and variability of the solid matrix. Studies of exploding thin film excitation of aqueous solution micro samples suggest that concomitant effects are not severe and, in general, are significantly less than those associated with arc excitation [14]. Only when the total sample mass approached the mass of the thin film $(\sim 13 \mu \mathrm{g})$ was a general intensity diminution observed.

When powder samples arc analyzed dircetly as solids, a distinction between interparticle and intra-particle concomitant effects may be useful. The former may be more characteristic of particle collections such as those often of interest in urban atmospheric studies. Individual particles within these collections often are dominated by a single component such as carbon, silica, or $\mathrm{NaCl}$. If the sample particles do not interact during vaporization, these inter-particle effects should be minimal. Intra-particle effects such as those associated with glasses and metallic solid solutions, may be more significant, since particle vaporization rates may vary with sample composition. For the materials used in the studies reported here, the preparation of reliable standards for the study of intra-particle concomitant effects would be very difficult. Studies are planned, however, for crushed glass samples.

For the experiments reported here, two analyte materials were chosen, VC to illustrate a refractory material and $\mathrm{Mn}$ metal as a non-refractory one. The concomitant species chosen were $\mathrm{NaCl}$, graphite and $\mathrm{Al}_{2} \mathrm{O}_{3}$. All particles used in this study, analyte as well as matrix, has an average particle diameter of less than $5 \mu \mathrm{m}$. This ensures good sampling statistics as well as promoting more complete particle vaporization.

Results for Mn and VC are shown in Table 4. Here the amount of Mn was held constant and the amount of concomitant species varied from zero to $99 \%$ of the total sample mass. All line intensities are normalized to the values obtained at zero matrix concentration. Neither matrix produced a statistically significant change in the Mn line intensity. These results are particularly encouraging considering the great differences in matrix properties. Results for VC again show little to suggest significant inter-particle concomitant effects over this range of sample and concomitant mass.

It is significant that no analyte line intensity changes are observed with total sample mass as large as $100 \mu \mathrm{g}$. Previous studies with lower mass, smaller surface area A1 films [14] showed significant analyte line intensity diminution when the total sample mass exceeds about $10 \mu \mathrm{g}$. The greater tolerance for large samples indicated in the present study may result from the more massive, larger surface area films used or the more disperse nature of the sample on the firm surface. Scanning electron microscope examination of aqueous solution sample residues on $\mathrm{Ag}$ thin films after evaporation of the water revealed heavy, crust-like formations of analyte material. Powder samples suspended in isopropyl alcohol resulted in relatively isolated particles on the film surface after evaporation of the alcohol.

[16] R. D. Sacks, Treatise on Analytical Chemistry (Edited by P. J. Elving and I. M. KolTHOFF), 2nd edition. Wiley, New York (1980). 
Table 4. Effect of concomitant on analyte line intensity

\begin{tabular}{|c|c|c|c|c|}
\hline Analyte & Concomitant & Amount $(\mu \mathrm{g})$ & $\begin{array}{l}\text { Normalized analytc } \\
\text { line intensity }\end{array}$ & $\begin{array}{c}\text { Relative S.D. } \\
(\%)\end{array}$ \\
\hline \multirow[t]{4}{*}{$0.5 \mu \mathrm{g} \mathrm{Mn}$} & $\mathrm{NaCl}$ & 0 & 1.00 & 7.3 \\
\hline & & 0.5 & 1.20 & 9.5 \\
\hline & & 4.5 & 0.92 & 13.2 \\
\hline & & 49.5 & 1.08 & 11.7 \\
\hline \multirow[t]{5}{*}{$1.0 \mu \mathrm{g} \mathrm{Mn}$} & Graphite & 0 & 1.00 & 10.2 \\
\hline & & 1.0 & 0.90 & 10.0 \\
\hline & & 9.0 & 0.97 & 14.4 \\
\hline & & 19.0 & 1.03 & 13.1 \\
\hline & & 99.0 & 1.01 & 15.5 \\
\hline \multirow[t]{4}{*}{$0.5 \mu \mathrm{gVC}$} & $\mathrm{NaCl}$ & 0 & 1.00 & 7.2 \\
\hline & & 0.5 & 1.20 & 11.1 \\
\hline & & 4.5 & 1.07 & 18.6 \\
\hline & & 49.5 & 1.24 & 17.9 \\
\hline \multirow[t]{6}{*}{$1.0 \mu \mathrm{g} \mathrm{VC}$} & Graphite & 0 & 1.00 & 10.2 \\
\hline & & 1.0 & 1.00 & 7.1 \\
\hline & & 4.0 & 1.10 & 8.5 \\
\hline & & 9.0 & 1.09 & 7.4 \\
\hline & & 19.0 & 1.04 & 4.7 \\
\hline & & 99.0 & 0.99 & 6.7 \\
\hline \multirow[t]{7}{*}{$1.0 \mu \mathrm{g} \mathrm{VC}$} & $\mathrm{Al}_{2} \mathrm{O}_{3}$ & 0 & 1.00 & 22.0 \\
\hline & & 1.0 & 1.17 & 14.4 \\
\hline & & 2.0 & 1.20 & 15.1 \\
\hline & & 3.0 & 1.11 & 9.3 \\
\hline & & 4.0 & 1.30 & 8.7 \\
\hline & & 9.0 & 1.19 & 13.3 \\
\hline & & 19.0 & 0.92 & 12.1 \\
\hline
\end{tabular}

\section{Particle Size Effects}

The analytical curves in Fig. 3 were obtained from powder samples containing particles ranging from less than 5 to over $70 \mu \mathrm{m}$ in diameter. It is unlikely that complete vaporization of the larger particles can occur in the time frame of these experiments. Figure 4 shows analytical curves obtained for three different particle size fractions of VC powder samples. Over the limited concentration range of one order of magnitude the curves are nearly linear, and they are parallel within experimental error. This suggests that particle interaction is insignificant.

The intensity of the analyte emission line increases significantly with decreasing particle diameter or with increasing total surface area of the sample. This indicates incomplete vaporization of the larger particles. While this observed particle size effect

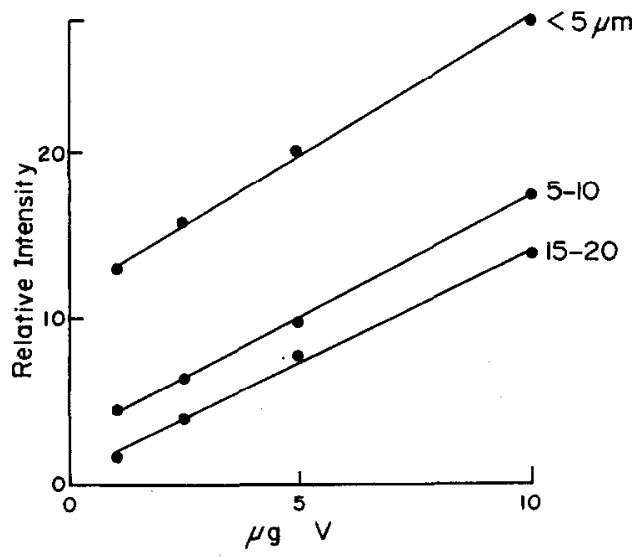

Fig. 4. Analytical curves for three particle size samples of VC. 
Table 5. Average particle size from commercially sieved powders

\begin{tabular}{crrrr}
\hline & \multicolumn{5}{c}{ Measured size } \\
\cline { 2 - 4 } $\begin{array}{c}\text { Nominal } \\
\text { size range } \\
(\mu \mathrm{m})\end{array}$ & $\mathrm{Ni}$ & $\mathrm{ZrC}$ & $\mathrm{VC}$ & $\mathrm{Mn}$ \\
\hline$>30$ & 53.0 & 67.0 & 54.7 & 49.5 \\
$30-20$ & 34.0 & 36.5 & 22.0 & 29.5 \\
$20-15$ & 17.0 & 23.5 & 16.5 & 24.5 \\
$15-10$ & 12.0 & 20.0 & 14.6 & 18.2 \\
$10-5$ & 7.5 & 12.2 & 8.9 & 12.5 \\
$<5$ & 3.6 & 4.1 & 2.8 & 5.3 \\
\hline
\end{tabular}

may be useful if particle size information is sought, generally it is deleterious in the quantitative analysis of powder samples. Therefore, a study was undertaken to explore the extent of particle size effects for different circuit parameters and support gas composition in the hope of finding conditions which would reduce these effects.

Keller and Penning [17] showed that the explosive vaporization of metal foils produces strong, planar shock waves. While the strength of shock waves produced by exploding thin films may be lower [18], studies of particle-shock wave interactions may provide a useful starting point for a discussion of possible particle vaporization processes.

TYTE [19] has shown that the rate of mass loss, $-\mathrm{dm} / \mathrm{d} t$, from a particle under shock

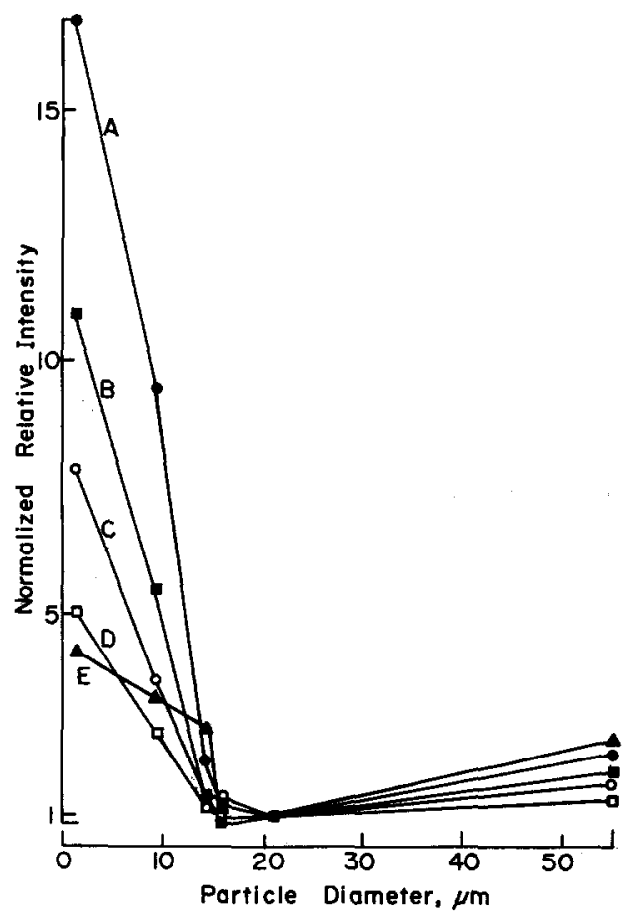

Fig. 5. Particle size effects for VC powder samples. All explosions were conducted at 700 torr. (A) Ar, $180 \mathrm{~J}, 4 \mathrm{kV}, 4.6 \mu \mathrm{H}$; (B) Ar, $180 \mathrm{~J}, 4 \mathrm{kV}, 17 \mu \mathrm{H}$; (C) Ar- $\mathrm{O}_{2}, 180 \mathrm{~J} ; 4 \mathrm{kV}, 17 \mu \mathrm{H}$; (D) $\mathrm{Ar}-\mathrm{O}_{2}, 240 \mathrm{~J}, 4 \mathrm{kV}, 17 \mu \mathrm{H}$; (E) $\mathrm{Ar}-\mathrm{O}_{2}, 375 \mathrm{~J}, 5 \mathrm{kV}, 22 \mu \mathrm{H}$. The intensities have been separately normalized to unity within each set of conditions. The actual values are given in Table 6.

[17] D. V. Keller and J. R. Penning, Exploding Wires (Edited by W. G. Chace and H. K. Moore), Vol. 2, p. 263. Plenum, New York (1962).

[18] D. V. Duchane, Ph.D. Dissertation. University of Michigan, Ann Arbor, MI (1978).

[19] D. C. TYTE, J. Appl. Phys. 37, 801 (1966). 
wave plasma conditions is related to the thermal energy flux $Q$ at the particle surface, an effective latent heat of sublimation $\varepsilon$ and the particle surface area $A$. Thus,

$$
-\frac{\mathrm{d} m}{\mathrm{~d} t}=\frac{A}{\varepsilon} Q
$$

where

$$
Q=h\left(T_{g}-T_{s}\right)
$$

Here, $h$ is the convective heat transfer coefficient, and $T_{\mathrm{g}}$ and $T_{s}$ are the kinetic temperatures of the plasma gas and the particle surface, respectively. These equations can be combined and integrated to give,

$$
r_{0}-r_{t}=(h t / \rho \varepsilon)\left(T_{g}-T_{s}\right),
$$

where $r_{0}$ and $r_{t}$ are the original particle radius and its radius at time $t$, respectively, and $\rho$ is the particle density. Thus, to increase the change in particle radius (increase vaporization), it is necessary to increase the plasma temperature, the plasma-particle interaction time or the convective heat transfer coefficient. The latter two may be more easily manipulated than the former.

Table 5 presents the average maximum particle dimension for each size fraction and compound studied. To explore the variation in intensity with particle size, $5.0 \mu \mathrm{g}$ of the powder sample was applied to each film, and four determinations were averaged. Figure 5 shows the effects of various experimental conditions on the magnitude of the particle size effect for VC. Since the range of intensity values with particle size rather than the actual values is of greater interest, all intensity values are separately normalized within each set of experimental conditions to the intensity of one particle size.

Curve A was obtained from explosions conducted at 700 torr in Ar using $180 \mathrm{~J}$, $4.0 \mathrm{kV}$ discharges. A more than 16 -fold increase in intensity is observed for the smallest particles relative to the larger ones. Curve B was obtained under similar conditions except an inductor was added to the circuit which increased the total circuit inductance from 4.6 to $17 \mu \mathrm{H}$. This increases the duration of the first current halfcycle in the oscillatory discharge train from 30 to $60 \mu \mathrm{s}$. The observed decrease in particle size effect probably is due to more efficient particle vaporization in the longer first current halfcycle. Previous studies with exploding metal wires [20] and foils [21] indicate that the plasma reforms during the second and subsequent halfcycles in a more diffuse, lower current density mode, which may not be effective in particle vaporization.

The data for curve $\mathrm{C}$ were obtained by maintaining the explosion conditions as for curve $\mathrm{B}$ except the atmosphere in the chamber was changed from $\mathrm{Ar}$ to an $\mathrm{Ar}-\mathrm{O}_{2}$ $(60-40 \%)$ mixture. In addition to an increase in line intensity (Table 6) and decrease in

Table 6. Particle size data for VC

\begin{tabular}{cccccc}
\hline & \multicolumn{5}{c}{ Relative intensities } \\
\cline { 2 - 6 } $\begin{array}{c}\text { Average particle } \\
\text { size }(\mu \mathrm{m})\end{array}$ & $\begin{array}{c}\mathrm{Ar}, 180 \mathrm{~J}, \\
4.6 \mu \mathrm{H}\end{array}$ & $\begin{array}{c}\mathrm{Ar}, 180 \mathrm{~J}, \\
17 \mu \mathrm{H}\end{array}$ & $\begin{array}{c}\mathrm{Ar}-\mathrm{O}_{2}, 180 \mathrm{~J}, \\
17 \mu \mathrm{H}\end{array}$ & $\begin{array}{c}\mathrm{Ar}-\mathrm{O}_{2}, 240 \mathrm{~J}, \\
17 \mu \mathbf{H}\end{array}$ & $\begin{array}{c}\mathrm{Ar}-\mathrm{O}_{2}, 375 \mathrm{~J}, \\
22 \mu \mathbf{H}\end{array}$ \\
\hline 54.7 & 29.9 & 32.4 & 42.4 & 62.8 & 159.3 \\
22.0 & 13.3 & 17.1 & 25.0 & 45.7 & 90.4 \\
16.5 & 15.9 & 12.5 & 32.2 & 43.8 & 84.0 \\
14.6 & 28.2 & 24.7 & 35.5 & 50.3 & 189 \\
8.9 & 125 & 94.4 & 92.2 & 121 & 275 \\
2.8 & 223 & 188 & 199 & 230 & 358 \\
\hline
\end{tabular}

[20] R. D. Sacks and J. A. Holcombe, Appl. Spectry 28, 518 (1974).

[21] C. S. LiNG, Ph.D. Dissertation. University of Michigan, Ann Arbor, MI (1977). 
background intensity [15], a significant decrease in particle size effect is observed. This suggests more complete vaporization of the larger particles.

There is much evidence to confirm that addition of polyatomic gases to Ar discharge plasmas generated by inductively coupled plasma devices results in significant changes in the plasma properties and thus in the vaporization characteristics of small particles in the plasma [8]. These changes include a reduction in Ar emission continuum [22-24], an increase in gas enthalpy [8], and, in the case of $\mathrm{O}_{2}$, an increase in plasma temperature [25,26]. CAPIrElli [27] has shown that the addition of only $8 \% \mathrm{~N}_{2}$ to $\mathrm{Ar}$ in an atmospheric pressure inductively coupled discharge increases by $80 \%$ the heat transferred to a $60 \mu \mathrm{m} \mathrm{Al} \mathrm{O}_{3}$ particle. This results from an increase in the thermal conductivity of the plasma with an attendant increase in the convective heat transfer coefficient. BARNES and NIKDEL [8] used computer simulations to study the decomposition of $\mathrm{Al}_{2} \mathrm{O}_{3}$ particles in $\mathrm{Ar}$ and $\mathrm{N}_{2}$ supported inductively coupled plasmas. They concluded that, over a wide range of input power, $\mathrm{N}_{2}$ results in more efficient particle decomposition. An increase in thermal conductivity of the plasma and possibly an increase in plasma temperature thus seem reasonable explanations for the reduced particle size effects observed in this study in the $\mathrm{Ar}-\mathrm{O}_{2}$ mixture. However, since the nature of the interaction between the plasma and the sample particles is virtually unknown, these explanations must be considered very speculative.

Curve D was obtained under the same conditions as curve $C$ except the discharge energy was increased from 180 to $240 \mathrm{~J}$ by adding additional capacitance to the circuit. This increases the duration of the first current halfcycle from 60 to $70 \mu \mathrm{s}$. Again, a significant decrease in particle size effect is observed.

Adding additional inductance to the circuit to obtain a total of $22 \mu \mathrm{H}$ as well as increasing the discharge energy from 240 to $375 \mathrm{~J}(5.0 \mathrm{kV}, 30 \mu \mathrm{F})$ decreases the intensity range further as can be seen in curve $\mathrm{E}$. However, this set of conditions is analytically undesirable since the high discharge energy results in a significant increase in background intensity.

The relative intensity values from the data used in Fig. 5 are summarized in Table 6. Caution should be used when comparing intensity values for a given particle size under different conditions, since separate, often widely separated studies are involved. However, inferences can be drawn from differences in intensity values from different particle sizes for a given set of experimental conditions.

In all cases, the $54.7 \mu \mathrm{m}$ particles produced intensity values greater than the $22 \mu \mathrm{m}$ ones. For three of the five sets of conditions, the $16.5 \mu \mathrm{m}$ particles produced the lowest intensity values. These unexpected results, which also were observed for large particles of other compounds, may be due to an increased fraction of aggregates in the larger particle size fractions. Figure 6 shows an clectron photomicrograph of particles from the $22 \mu \mathrm{m}$ size fraction of VC. A single particle and a typical aggregate are observed. The increased intensity observed for the largest size fraction, which consists mainly of these aggregated, may be due to more efficient heat transfer to these larger surface area particles or to their fractionation during the explosion [28]. This aggregate effect is pronounced for all materials studied with average particle size of $30 \mu \mathrm{m}$ or greater.

Table 7 summarizes particle size data for $\mathrm{ZrC}$ and $\mathrm{Mn}$ samples under two sets of experimental conditions. The aggregate effect is even more pronounced for $\mathrm{ZrC}$ than for VC. The Mn powder samples, however, show only minor aggregate formation. Of prime analytical significance are the 1.1 and 0.91 values for the intensity ratios of the smallest to the next smaller particles of $\mathrm{Mn}$ and $\mathrm{ZrC}$, respectively, in the $\mathrm{Ar}-\mathrm{O}_{2}$

[22] S. Greenfield, I. L. Jones, C. T. Berry and L. G. Bunch, Proc. Soc. Anal. Chem. 2, 111 (1965).

[23] S. GREENFIELD, Metron 3, 224 (1971).

[24] J. F. Adler and J. M. Mermet, Spectrochim. Acta 28B, 421 (1973).

[25] H. U. Eckert, F. L. Kelly and H. N. Olsen, J. Appl. Phys. 39, 1846 (1968).

[26] V. M. Goldfarb and V. Kh. Goikhman, J. Appl. Spectry 8, 193 (1968).

[27] M. Capitelli, Comb. Flames 15, 23 (1970).

[28] G. J. Bastians and G. M. Hiefije, Anal. Chem. 46, 901 (1974). 


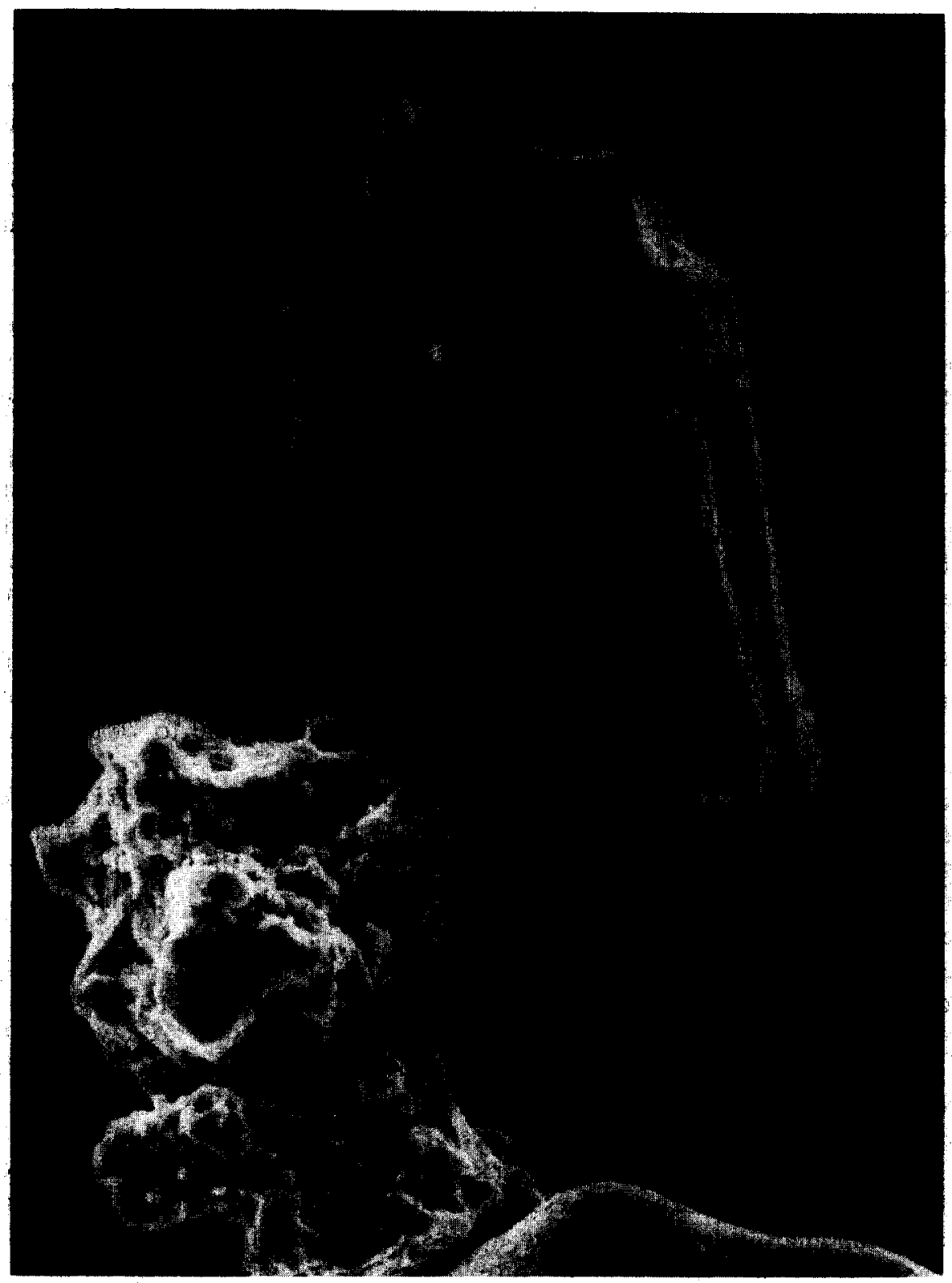

Fig. 6. Sanning electron micrograph of VC particles from the $22 \mu \mathrm{m}$ size fraction showing a single particle and a large aggregate.

mixture. These values are not statistically different from unity based on the measurement precision and indicate that the two smallest particle size powders of both materials are vaporized completely in the $\mathrm{Ar}-\mathrm{O}_{2}$ mixture. This prompted a study to compare intensities obtained from aqueous samples and powder samples with an average particle size of less than $5 \mu \mathrm{m}$.

\section{Analysis of Small Particle Powders Using Aqueous Standards}

In this study, intensities were compared from $10 \mu \mathrm{l}$ aqueous solution samples and powder samples suspended in isopropyl alcohol. Explosions were conducted at 700 torr in an $\mathrm{Ar}-\mathrm{O}_{2}(60-40)$ mixture using $240 \mathrm{~J}, 4 \mathrm{kV}, 22 \mu \mathrm{H}$ discharges. Results are shown in Table 8 . In all cases, the intensity ratio of aqueous to solid samples is nearly unity. This is true even for $\mathrm{Zr}$ where the $\mathrm{Zr}\left(\mathrm{SO}_{4}\right)_{2} \cdot 4 \mathrm{H}_{2} \mathrm{O}$ decomposes at $680 \mathrm{~K}$ and $\mathrm{ZrC}$ solid boils at $5370 \mathrm{~K}$. 
Table 7. Particle size data for $\mathrm{ZrC}$ and $\mathrm{Mn}$

\begin{tabular}{cccc}
\hline & & \multicolumn{2}{c}{ Relative intensity } \\
\cline { 3 - 4 } & $\begin{array}{c}\text { Average particle } \\
\text { size }(\mu \mathrm{m})\end{array}$ & $($ Ar, $180 \mathrm{~J}, 4.6 \mu \mathrm{H})$ & $\left(\mathrm{Ar}-\mathrm{O}_{2}, 375 \mathrm{~J}, 22 \mu \mathrm{H}\right)$ \\
\hline $\mathrm{ZrC}$ & 67.0 & 92.2 & 151 \\
& 36.5 & 14.8 & 67.5 \\
& 23.5 & 6.2 & 52 \\
& 20.0 & 27.2 & 104 \\
& 12.2 & 57.8 & 212 \\
$\mathrm{Mn}$ & 4.1 & 103 & 190 \\
& 49.5 & 20.0 & 37.3 \\
& 29.5 & 14.2 & 32.8 \\
& 24.5 & 14.4 & 102 \\
& 18.2 & 45.4 & 325 \\
& 12.5 & 152 & 359 \\
\hline
\end{tabular}

These results indicate that small particles are vaporized completely in the $\mathrm{Ar}-\mathrm{O}_{2}$ mixture. More importantly, they imply that aqueous standards may be used in the analysis of small particles, ranging in size up to at least $5 \mu \mathrm{m}$ and probably up to at least $10 \mu \mathrm{m}$. This is confirmed in Fig. 7. Here, analytical curves are presented for $\mathrm{Ni}$ using aqueous $\mathrm{Ni}\left(\mathrm{NO}_{3}\right)_{2} \cdot 6 \mathrm{H}_{2} \mathrm{O}$ standards and for $\mathrm{V}$ using aqueous $\mathrm{NH}_{4} \mathrm{VO}_{3}$ standards. The point labeled A on the Ni curve represents a $1.4 \mu \mathrm{g}$ Ni powder sample. Points $\mathrm{B}, \mathrm{C}$ and $D$ on the $V$ curve are from $V C, V_{2} \mathrm{O}_{3}$ and $\mathrm{V}_{2} \mathrm{~S}_{3}$ powder samples, respectively. All powder samples had an average particle size of less than $5 \mu \mathrm{m}$.

Linear regression analysis of the data points from the standards in Fig. 7 was used to determine the weights of the solid samples. Table 9 summarizes the results. The relative errors range from 3 to $15 \%$. This demonstrates that small particles can be analyzed directly using aqueous standards. For the materials tested, the boiling point and compound form seem relatively unimportant. Refractory as well as non-refractory solids can be analyzed using the same analytical curve.

\section{Limits of Detection}

Detection limits were determined for the elements in Table 10. These values are defined as the minimum amount of the element required to produce a line intensity over background equal to three times the intensity equivalent of the r.m.s. noise on the microdensitometer trace in a nearby wavelength region of continuum background. To obtain reliable extrapolated detection limits, the SAl plates were prefogged to an absorbance of 0.25 , which is sufficient to ensure operation on the linear region of the emulsion calibration curve. All the samples used in this study passed through a 5- $\mu \mathrm{m}$ pore diameter sieve. Explosions were conducted at 700 torr in an $\mathrm{Ar}-\mathrm{O}_{2}$ (60-40) mixture using $240 \mathrm{~J}, 4 \mathrm{kV}, 22 \mu \mathrm{H}$ discharges.

Table 8. Relative intensity of solid samples compared to aqueous samples

\begin{tabular}{ccccc}
\hline $\begin{array}{l}\text { Powder } \\
\text { sample }\end{array}$ & $\begin{array}{c}\text { Relative } \\
\text { intensity }\end{array}$ & $\begin{array}{c}\text { Aqueous } \\
\text { sample }\end{array}$ & $\begin{array}{c}\text { Relative } \\
\text { intensity }\end{array}$ & $\begin{array}{c}\text { Intensity ratio } \\
\text { aqueous/solid }\end{array}$ \\
\hline $\mathrm{VC}$ & 164 & $\mathrm{NH}_{4} \mathrm{VO}_{3}$ & 188 & 1.15 \\
$\mathrm{Ni}$ & 75 & $\mathrm{Ni}\left(\mathrm{NO}_{3}\right)_{2} \cdot 6 \mathrm{H}_{2} \mathrm{O}$ & 67 & 0.90 \\
$\mathrm{ZrC}$ & 79 & $\mathrm{ZrSO}_{4} \cdot 4 \mathrm{H}_{2} \mathrm{O}$ & 84 & 1.05 \\
$\mathrm{Mn}$ & 367 & $\mathrm{Mn}^{\left(\mathrm{NO}_{3}\right)_{2} \cdot 4 \mathrm{H}_{2} \mathrm{O}}$ & 364 & 1.02 \\
$\mathrm{Mo}_{2} \mathrm{C}$ & 88 & $\left(\mathrm{NH}_{4}\right)_{2} \mathrm{MoO}_{4}$ & 91 & 1.03 \\
\hline
\end{tabular}




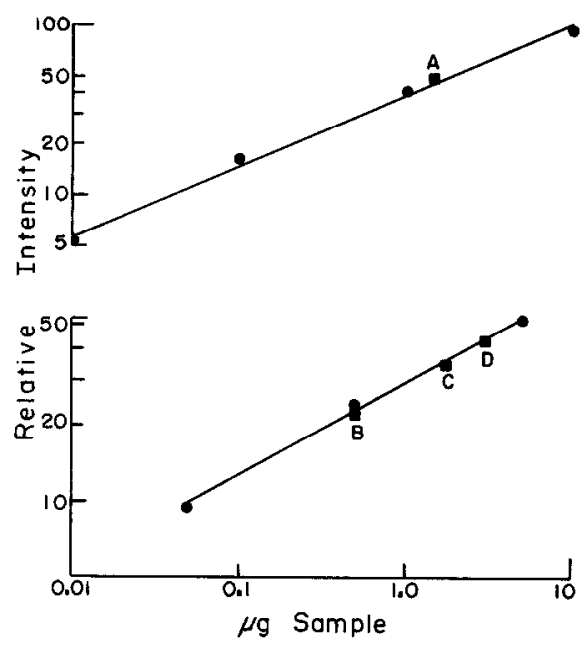

Fig. 7. Analytical curves for $\mathrm{Ni}$ and $\mathrm{V}$ using $10 \mu \mathrm{l}$ aqueous solution standards. The points labeled $\mathrm{A}, \mathrm{B}, \mathrm{C}$ and $\mathrm{D}$ correspond to $\mathrm{Ni}, \mathrm{VC}, \mathrm{V}_{2} \mathrm{O}_{3}$ and $\mathrm{V}_{2} \mathrm{~S}_{3}$, respectively all introduced as powders.

Eight of the ten elements tested have sub-ng detection limits. The values in Table 10 are very similar to values reported by DuCHANE and SACKs [14] for aqueous solution samples determined by exploding thin film excitation with $13 \mu \mathrm{g}$ Al films exploded in dry air at 300 torr using $180 \mathrm{~J}, 4 \mathrm{kV}$ discharges. It is interesting to note that for five of the ten elements tested, ion lines are stronger than neutral-atom lines in the wavelength region studied. This emphasizes the spark-like nature of exploding thin film plasmas.

\section{Determination of Powder Samples Collected on Metallized Membrane Filters}

This report has shown that solid powder micro samples can be determined quantitatively with minimal preparation using the exploding thin film technique. Dissolution of the sample, which is difficult to the say the least when dealing with refractory materials, becomes unnecessary. In addition, the range of particle sizes for which vaporization is complete and aqueous solution standards can be used is the range of most intense interest in studies of atmospheric particulate material. Thus, exploding thin films may provide an attractive alternative for the determination of metallic elements in suspended particles collected on metallized membrane filters.

\subsection{Film-membrane characteristics}

Thin Ag films prepared on Nuclepore polycarbonate mebranes appear very uniform and quite reflective. They adhere well and can be rubbed off only with difficulty. Since the metal vapor should deposit only on surfaces with projected area normal to the vapor trajectory, pore clogging by the metal film should be insignificant. In addition, the $280 \AA$ film thickness is small with respect to the $3 \mu \mathrm{m}$ pore diameter. Membranes which were metallized only on half their surface were inspected with a scanning electron microscope. As can be seen in Fig. 8, the pore character and size have not

Table 9. Determination of powders with aqueous standards

\begin{tabular}{lcccc}
\hline \multicolumn{1}{c}{ Standard } & Sample & $\begin{array}{c}\text { Amount } \\
\text { added }(\mu \mathrm{g})\end{array}$ & $\begin{array}{c}\text { Amount } \\
\text { found }(\mu \mathrm{g})\end{array}$ & $\begin{array}{c}\text { Relative } \\
\text { error }(\%)\end{array}$ \\
\hline $\mathrm{Ni}\left(\mathrm{NO}_{3}\right)_{2} \cdot 6 \mathrm{H}_{2} \mathrm{O}$ & $\mathrm{Ni}$ & 1.4 & 1.6 & 14 \\
$\mathrm{NH}_{4} \mathrm{VO}_{3}$ & $\mathrm{VC}$ & 0.5 & 0.53 & 6 \\
$\mathrm{NH}_{4} \mathrm{VO}_{3}$ & $\mathrm{~V}_{2} \mathrm{O}_{3}$ & 1.76 & 1.82 & 3 \\
$\mathrm{NH}_{4} \mathrm{VO}_{3}$ & $\mathrm{~V}_{2} \mathrm{~S}_{3}$ & 3.0 & 3.45 & 15 \\
\hline
\end{tabular}




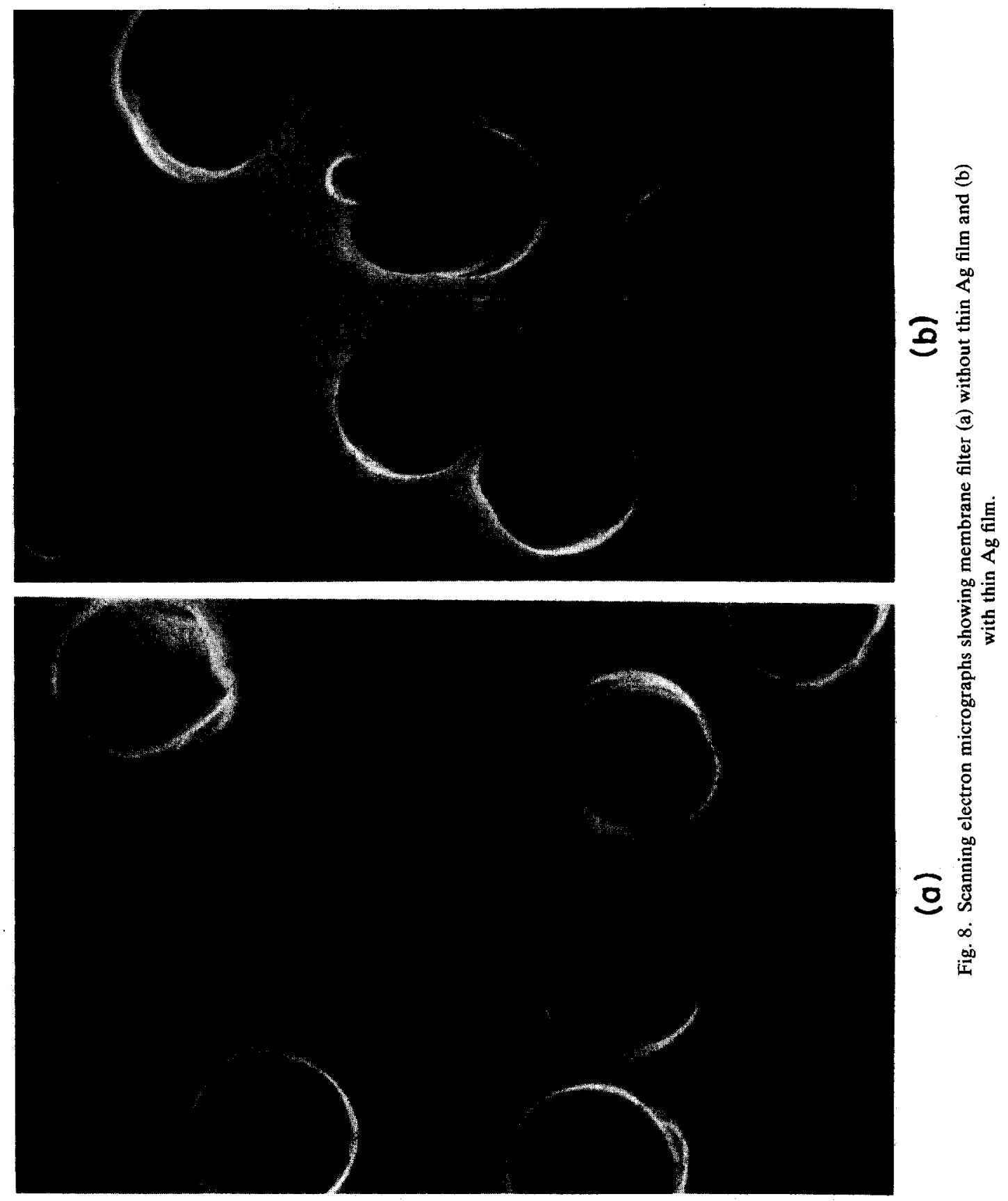


Table 10. Detection limits for small-particle powder samples

\begin{tabular}{llll}
\hline Element & $\begin{array}{c}\text { Chemical } \\
\text { form }\end{array}$ & $\begin{array}{c}\text { Analysis } \\
\text { line (nm) }\end{array}$ & $\begin{array}{c}\text { Detection } \\
\text { limit (ng) }\end{array}$ \\
\hline $\mathrm{Cd}$ & $\mathrm{CdF}_{2}$ & (II) 226.5 & 0.34 \\
$\mathrm{Co}$ & $\mathrm{Co}_{\mathrm{C}}$ & (I) 345.3 & 0.21 \\
$\mathrm{Cr}$ & $\mathrm{CrCO}_{3}$ & (II) 284.3 & 0.008 \\
$\mathrm{Fe}$ & $\mathrm{Fe}$ & (I) 303.7 & 16 \\
$\mathrm{Mo}$ & $\mathrm{Mo}{ }_{2} \mathrm{C}$ & (I) 313.2 & 0.37 \\
$\mathrm{Mn}$ & $\mathrm{Mn}$ & (II) 294.9 & 0.0095 \\
$\mathrm{Ni}$ & $\mathrm{Ni}$ & (I) 341.4 & 0.035 \\
$\mathrm{~Pb}$ & $\mathrm{~Pb}$ & (I) 283.3 & 4.3 \\
$\mathrm{~V}$ & $\mathrm{VC}$ & (II) 310.2 & 0.011 \\
$\mathrm{Zr}$ & $\mathrm{ZrC}$ & (II) 343.8 & 0.0057 \\
\hline
\end{tabular}

been altered significantly by the Ag thin film. When the metallized filter was subjected to suction and air flow, no deterioration of the film was observed.

Spectra from exploding metallized membranes show numerous lines from neutralatom and singly ionized $\mathrm{Ag}$. The $\mathrm{Cu}$ neutral-atom resonance lines at 324.7 and $327.4 \mathrm{~nm}$ were quite strong. This probably results from sampling of the copper cassette by the high current plasma. Continuum intensity was lower than expected based on the film mass [29]. Since the maximum width of the film $(41 \mathrm{~mm})$ normal to the current path is significantly greater than any films previously studied, lower current density in the plasma which forms after film vaporization may be responsible for the lower continuum intensity.

Unlike the polyethylene and polypropylene substrates used in previous studies, the very thin and fragile membranes are partially or completely destroyed by the explosions. A direct comparison of the spectra obtained from $\mathrm{Ag}$ films exploded from membrane filters and from polypropylene strips showed no detectable impurity radiation from the membranes despite their consumption during the explosions. Since the manufacturer of the membranes lists typical impurity levels which are significantly greater than detection limits found in this report, it appears that while the membrane is destroyed, it is not atomized to a significant extent. This supports the idea that the sample is vaporized in the plasma and not vaporized with the film.

Preliminary studies with the metallized membranes indicated that sample particles frequently were blown off the membrane during chamber pumpdown and subsequent filling with the $\mathrm{Ar}-\mathrm{O}_{2}$ plasma support gas. Thus, all explosions were conducted in room air at atmospheric pressure. A discharge energy of $281 \mathrm{~J}$ at $5 \mathrm{kV}$ was necessary to vaporize completely the $\mathrm{Ag}$ film. At lower energies, the edge of the circular film was left unvaporized. This results in lower intensity and poorer precision for $\mathrm{Ag}$ lines from the film material.

\subsection{Sample introduction and analysis}

Four test materials were investigated, $\mathrm{ZrC}, \mathrm{VC}, \mathrm{CdF}_{2}$ and $\mathrm{Ni}$. These samples were not sieved and contained significant numbers of large particles. To reduce weighing errors, each test material was mixed with $\mathrm{Al}_{2} \mathrm{O}_{3}$ powder in a ratio of 1-99. Four determinations were made for each element. All spectra were obtained on a multielement basis.

Microdensitometer traces of spectra from the exploding metallized filters, both with and without sample, are shown in Fig. 9. The lower trace in each frame illustrates the spectrum of the thin film without the sample. In the wavelength region investigated (290-370 nm), relatively intense neutral-atom lines of $\mathrm{Cd}$ and $\mathrm{Ni}$ and ion lines of $\mathrm{V}$ and $\mathrm{Zr}$ are observed. The spectra of $\mathrm{V}$ and $\mathrm{Zr}$ are particularly significant considering the very high boiling points of their carbides. 


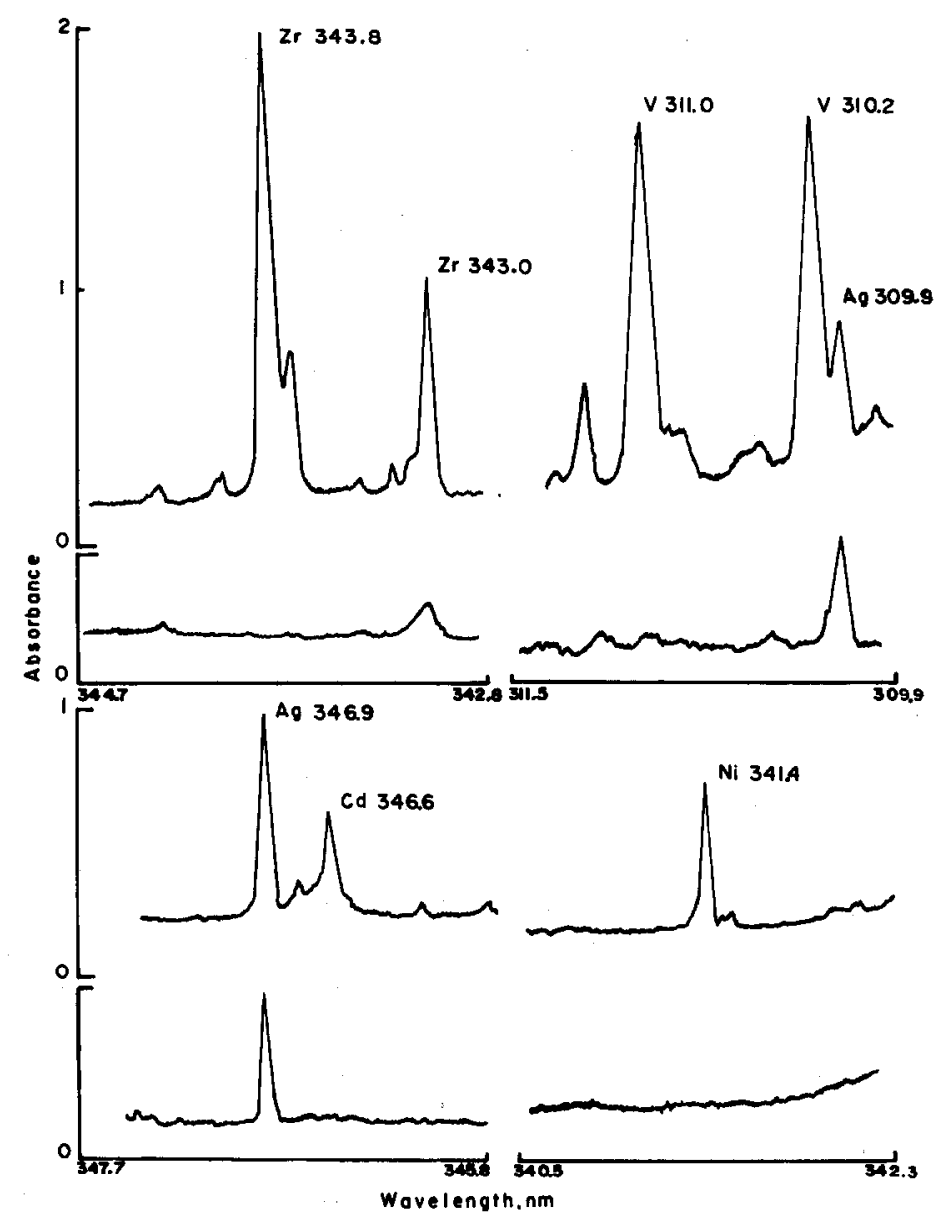

Fig. 9. Microdensitometer traces from exploding thin film spectra showing emission lines of $\mathrm{V}$, $\mathrm{Zr}, \mathrm{Cd}$ and $\mathrm{Ni}$ from powder samples. Explosions were conducted in room air at atmospheric pressure using $5 \mathrm{kV}, 281 \mathrm{~J}$ discharges. The lower trace in each frame is from the $\mathrm{Ag}$ thin film without sample.

The relative standard deviations of measured intensities are $24,19,12$ and $21 \%$ for $\mathrm{Zr}, \mathrm{V}, \mathrm{Ni}$ and $\mathrm{Cd}$, respectively. The somewhat larger values obtained here compared to the values in Table 3 from alcohol suspensions may reflect variable sample loss by impactation during transport to the filter as well as the presence of large particles which are not completely atomized.

Detection limits were found for some selected elements using exploding metallized filters. These are listed in Table 11 and were obtained from powder samples which had not been separated into separate particle size fractions. The decreased powers of detection observed for these samples may be due to several factors such as loss of

Table 11. Detection limits for powder samples on metallized membrane filters

\begin{tabular}{lllll}
\hline Element & \multicolumn{1}{c}{$\begin{array}{c}\text { Chemical } \\
\text { form }\end{array}$} & $\begin{array}{c}\text { Analysis } \\
\text { line (nm) }\end{array}$ & $\begin{array}{c}\text { Detection } \\
\text { limit (ng) }\end{array}$ & $\begin{array}{c}\text { Detection } \\
\text { limit }^{*}\left(\mathrm{ng} \mathrm{m}^{-3}\right)\end{array}$ \\
\hline $\mathrm{Cr}$ & $\mathrm{CrCO}_{3}$ & (II) 284.3 & 2.9 & 4.8 \\
$\mathrm{Mn}$ & $\mathrm{MnSO}_{4} \cdot 4 \mathrm{H}_{2} \mathrm{O}$ & (II) 294.9 & 0.35 & 0.58 \\
$\mathrm{~V}$ & $\mathrm{VC}$ & (II) 310.2 & 0.032 & 0.053 \\
$\mathrm{Zr}$ & $\mathrm{ZrC}_{\mathrm{Cd}}$ & (II) 343.8 & 0.10 & 0.17 \\
$\mathrm{Ci}$ & $\mathrm{CdF}$ & (II) 226.5 & 1.87 & 3.11 \\
& $\mathrm{Ni}$ & (I) 341.4 & 2.64 & 4.4. \\
\hline
\end{tabular}

* Based on a $101 \mathrm{~min}^{-1}$ flow rate and a $1 \mathrm{~h}$ sampling time. 
sample during transport, and incomplete vaporization due to particle size and due to decreased current density arising from the increased thin film area. In addition, modification of the explosion chamber to permit use of the $\mathrm{Ar}-\mathrm{O}_{2}$ plasma support gas should result in greater analysis line-to-background ratios as well as more complete atomization of the sample. Studies are now under way to isolate and eliminate the sensitivity limiting factors. However, from these preliminary detection limits in Table 11 , the minimum detectable concentrations of these analytes in air were calculated, based on a $101 \mathrm{~min}^{-1}$ flow rate and a $1 \mathrm{~h}$ sampling time. These values were found to compare very favorably with literature values of detection limits for the direct X-ray fluorescence analysis of particulate material collected on filters [30].

This study indicates the feasibility for the direct determination of trace metals in suspended particulate material using exploding metallized filters as the collection, atomization and excitation device. Since airborne particles greater than $10 \mu \mathrm{m}$ in diameter are of relatively less concern, it is easy to envision a collection apparatus with a dichotomous sampler, so that only small particles are impacted onto the filter for analysis. Because of relatively severe particle size effects, dichotomous sampling often is used with X-ray fluorescence methods [9].

\section{Conclusions}

The studies reported here suggest that exploding thin film atomization and excitation might be used successfully for the direct analysis of several classes of materials generally considered difficult in terms of sample preparation. This includes materials for which $\mathrm{NHO}_{3}-\mathrm{HClO}_{4}$ digestion is insufficient to render soluble the inorganic portion of the sample. While high-temperature fusion and HF digestion procedures are useful in some cases, they are time consuming and risky in terms of sample loss and contamination.

The possible use of aqueous solution standards for the direct analysis of a wide variety of solid, powder materials is quite significant and warrants further consideration. If the sample particles are sufficiently small $(<10 \mu \mathrm{m})$, particle size effects appear negligible, and sampling statistics appear satisfactory. This should permit the use of the very simple alcohol suspension technique of sample introduction for a wide variety of powder materials. Solubility of sample components in the alcohol should not present a problem. While intra-particle concomitant effects need to be investigated, the apparent complete vaporization of all small particles independent of their boiling points suggests that these effects will not be severe.

More detailed studies are planned for several classes of real solid samples which can be ground into fine powders. These include glasses and other siliceous materials, soils, coals and ceramics. While the metallized membrane filter studies are very preliminary, they are very encouraging and have prompted a detailed study. This method of sample collection also will be evaluated for liquid suspensions of fine particles.

Acknowledgement -.-The authors acknowledge support of this study by the National Science Foundation through grant No. CHE76-11646 AO1.

[30] B. C. BegNoCHE and T. H RisBy, Anal. Chem. 47, 107 (1975). 